\title{
Modeling of the piezoceramic resonator electric loading conditions based on experimental data
}

\author{
Bezverkhyi O. I., Zinchuk L. P., Karlash V. L. \\ S. P. Timoshenko Institute of Mechanics, The National Academy of Sciences of Ukraine \\ 3, Nesterov str., 0305\%, Kyiv, Ukraine
}

(Received 16 March 2015)

\begin{abstract}
This paper is devoted to analysis of the electric loading conditions problem for piezoceramic resonators' forced vibrations. New simple experimental technique together with computing permits us to study many resonators' parameters: admittance, impedance, phase angles, power components, etc. for constant input voltage, constant sample voltage and constant sample current electric conditions based on experimental data for "as it is" regime. Such computer modeling makes it possible to decrease the experimental difficulties and to study in linear approximations the dependence of resonators' parameters on loading conditions. The fundamental modes of vibrations of a thin piezoelectric bar and high cylindrical shell are given as example. It is established that considerable admittance nonlinearity in constant voltage regime and its absence for constant current case are caused by different behavior of instantaneous power level.
\end{abstract}

Keywords: piezoceramic resonators, forced vibrations, electromechanical coupling factor, thin piezoelectric plates and shells, instantaneous power components

2000 MSC: $74-05,74 \mathrm{~F} 15,74 \mathrm{H} 45$

UDC: $534.1: 537.226 .86: 539.3$

\section{Introduction}

Piezoceramic elements, while performing similarly or better than electromagnetic ones, are more suitable for miniaturization's purpose [1-3]. When uniform mechanic stress is applied in a non-centered symmetric crystal or polarized piezoceramic sample there is a movement of positive and negative ions with respect to each other, creating an electric charge at the surface. This is a direct piezoelectric effect - a conversion of mechanical energy into electrical energy. When electric field is applied to the sample an elastic strain is produced. This is an inverse piezoelectric effect - a conversion of an electric energy into mechanical energy. When an alternating electric field is applied mechanic vibrations are induced, which at appropriate frequency cause mechanical resonance with great strains and stresses. A phenomenon of strain increasing due to accumulated electric energy is known as a piezoelectric resonance [4-7 etc]. Both direct and inverse piezoelectric effects are linear physical phenomena with respect to the induced fields.

Vibrations of piezoceramic elements are characterized by great electromechanical coupling between electric fields and elastic displacements or stresses. The internal physical processes nature in such bodies drives to the fact that mechanical displacements, strains and stresses, sample admittance, impedance or instantaneous power have both real and imaginary parts. Thus, it is possible to calculate any amplitude with accounting the energy losses only [5-10]. The analytic solutions for electro-elastic vibrations of simple geometric form bodies such as bars, rods, disks, circular or cylindrical rings etc [5-7] are used in standards for determination of the real parts of dielectric, elastic and piezoelectric coefficients.

Ref [10] was devoted to modeling of the loss-energy piezoceramic resonators by Van-Dyke-type electric equivalent networks with passive elements. It was shown that when the piezoelectric sample is excited by the constant voltage the instantaneous power in the sample increases at a resonance 
frequency in many times in respect to off-resonance case. When sample is excited by constant current an instantaneous power decreases at resonance frequency in same ratio. Thus, the reason of admittance curve nonlinearity at the constant voltage and its absence at the constant current is high or low level of an instantaneous power.

Imaginary parts of the dielectric, elastic and piezoelectric coefficients usually are determined at maxima/minima admittance, what was first proposed by Martin [11]. Very important role in energy losses belongs to mechanic quality factor $Q$, which differs for resonance and anti-resonance cases [12].

In Ref [13], on the example of famous problem of radial vibrations of thin piezoceramic full electrode disk, the expressions for instantaneous power were derived, and graphs of the admittance and power change near resonance/anti-resonance at constant voltage (with the constant amplitude) or the constant current (with the constant amplitude) were plotted. Calculations were performed in complex form with taking into account the experimentally determined mechanic, dielectric and piezoelectric energy losses. It was shown that for constant voltage regime the instantaneous power sharply increases near resonance but it decreases for the constant current regime. This accounts for the existence or absence of nonlinearity which was discovered in Ref [2].

This paper is devoted to analysis of the electric loading conditions problem for piezoceramic resonators' forced vibrations. An idea of the step-by-step voltage measuring in modern Mason's schema [14] is developed and method for the determination of phase shifts between admittance's or power's components with cosine law are used [8-10]. New simple experimental technique together with computing permits to study many resonators' parameters: admittance, impedance, phase angles, power components etc for constant input voltage, constant sample voltage, constant sample current and constant instantaneous power electric conditions based on experimental data for "as it is" regime. "As it is" regime for experimental investigation means that sample voltage, input voltage and loading resistor voltage are measured separately and consecutively. The regimes of constant voltage, constant currant constant power mean that their amplitudes are installed at the beginning of experiment and not changed for selected frequency range. Such experiments for frequency range near the fundamental mode of the thin disk radial vibrations have been described in paper [8]. It was shown that admittance's components and phase angles for constant sample current, constant sample voltage and constant input voltage exhibit the same results.

There are two various modeling technique in this paper: an iterative process and electric loading condition simulation. First model permits to determine the coupling coefficients and loss energy tangents on a base of measured maxima/minima admittance values. Second model serves for simulation of electric loading conditions and it is based on experimental measured data for "as it is" regime. Both models are very suitable for the decreasing of investigation difficulties.

Computer modeling makes possible to study in linear approximations the dependence of resonators' parameters from loading conditions.

The fundamental modes of thin piezoelectric bar [1-3,12,15-17] and high cylindrical shells [5] are given as example. It was established that admittance, impedance, phase shifts are independent from loading conditions. It was established that admittance, impedance, phase shifts are independent from loading conditions. High admittance nonlinearity in constant voltage regime and its absence for constant current case are created by different behavior of instantaneous power. The instantaneous power reaches maximum level at resonances for the constant sample voltage and at anti-resonances for the constant sample current. To modeling of constant power regime for the thin piezoelectric ceramic bar it is necessary to increase input voltage and sample voltage near resonance on $30-40 \%$ and in several times at anti-resonance with respect to off-resonance case.

\section{Admittance, impedance and power components for thin piezoceramic bars and rings}

Piezoelectric bars with transversal polarization became already a 'touchstone' in many experimental researches because their vibrations are described by simple mathematical formulas, and the first overtone

Mathematical Modeling and Computing, Vol. 2, No. 2, pp. 115-127 (2015) 
lies far from fundamental resonance as to frequency [5-12]. The mechanical and electric values of these structures are coupled between themselves by the so-called transversal coefficient of electromechanical coupling (EMC) $k_{31}$, that is why the longitudinal vibrations of such bars in foreign publications quite often name a $k_{31}$ mode [1-3,12].

In Refs $[8-10,13]$ it was shown that the piezoelectric resonator's admittance can be presented in calculations as imaginary conductivity of the inter-electrode sample capacitance $C_{0}$ multiplied by the ratio of anti-resonance $\Delta_{a}(x)$ to resonance $\Delta(x)$ determinants

$$
Y=j \omega C_{0} \frac{\Delta_{a}(x)}{\Delta(x)}
$$

where $j$ is the imaginary unit, $\omega$ is the angular frequency, $x$ is the dimensionless frequency, which depends on geometric sample's form.

For thin bar with thickness polarization and high cylindrical shell with radial polarization the following formulae were derived accordingly [5]

$$
\begin{gathered}
Y_{b}=j \omega C_{0}\left[1-k_{31}^{2}+\frac{k_{31}^{2} \sin x}{x \cos x}\right]=j \omega C_{0} \frac{\Delta_{a}(x)}{\Delta(x)}, \\
\Delta(x)=\cos (x), \quad \Delta_{a}(x)=\left(1-k_{31}^{2}\right) \Delta(x)+k_{31}^{2} \sin x / x ; \\
Y_{h k}=j \omega C_{0}\left[1-k_{p}^{2}+\frac{(1+\nu) k_{p}^{2} \omega_{r}^{2}}{2\left(\omega_{r}^{2}-\omega^{2}\right)}\right]=j \omega C_{0} \frac{\Delta_{a}(x)}{\Delta(x)}, \\
\Delta(x)=\omega_{r}^{2}-\omega^{2}, \quad \Delta_{a}(x)=\left(1-k_{p}^{2}\right) \Delta(x)+(1+\nu) k_{p}^{2} \omega_{r}^{2} / 2 .
\end{gathered}
$$

Here $j$ is the imaginary unit, $\omega$ and $\omega_{r}$ are the angular frequency and the resonant angular frequency respectively, $k_{31}$ and $k_{p}$ are the transverse coupling coefficient and the planar coupling coefficient, and $\nu$ is Poisson's ratio.

All the variables, functions and electro-elastic coefficients in (1)-(3) are complex $[4,8,13]$. The dimensionless frequency $x$ is determined for the thin bar case as

$$
x=\left(\rho s_{11}^{E}\right)^{1 / 2} \omega l / 2=\left(\rho s_{110}^{E}\right)^{1 / 2}\left(1-j s_{11 m} / 2\right) \omega l / 2=x_{1}-j x_{2}, \quad s_{11}^{E}=s_{110}^{E}\left(1-j s_{11 m}\right)
$$

and for the high cylindrical ring case as

$$
x=\omega / \omega_{r}=\omega R\left(\rho s_{11}^{E}\right)^{1 / 2}=\omega R\left(\rho s_{110}^{E}\right)^{1 / 2}\left(1-j s_{11 m} / 2\right)=x_{1}-j x_{2} .
$$

Here $l$ is the bar length, $R$ is exterior ring's radius, $x_{1}$ and $x_{2}$ are the real and imaginary parts of the complex dimensionless frequency $x, s_{11}^{E}$ is the complex elastic compliances, $\rho$ is the density.

Admittance (or full conductivity) characterizes sample's possibility to conduct the electric current and is determined as the ratio of the sample current to the sample voltage. This parameter is convenient near the resonance of piezoelectric sample where it reaches maximum value. But for anti-resonant frequency region it is more convenient to use impedance because it reaches its maximum value at antiresonance. The admittance $Y$ and the impedance $Z$ are in inverse ratio and for impedance calculation we can use the following simple relation

$$
Z=\frac{1}{Y}
$$

There are three characteristic power's components in sinusoidal alternative current circuit: the instantaneous power $P$ in volt-ampere (VA), which is voltage drop $U$ on some circuit area in some time moment multiplied on circuit's current $I$ in the same moment, the active power $P_{a}$ in watts (W), which is distinguished on active resistance and heats it, and the reactive power $P_{r e}$ in volt-ampere 
reactive (VAr), which is distinguished on reactive circuit's elements (inductances or capacitances) and creates electric or magnetic fields [13]

$$
P=U I, \quad P_{a}=U I \cos \alpha, \quad P_{r e}=U I \sin \alpha .
$$

When the piezoresonator's voltage is $U_{1}$ and the piezoresonator's current is $I_{0}$ we can write

$$
\begin{gathered}
U_{1}=I_{0} / Y, \quad I_{0}=U_{1} Y, \quad P=U_{1} I_{0}=I_{0}^{2} / Y=U_{1}^{2} Y, \\
P_{a}=P \cos \alpha, \quad P_{r e}=P \sin \alpha, \quad \alpha=\operatorname{arccot}\left(w_{1}\right), \quad w_{1}=\operatorname{Re}(Y) / \operatorname{Im}(Y) .
\end{gathered}
$$

These formulae permit us to realize in calculations the regimes of constant voltage $U_{1}=$ const, constant current $I_{0}=$ const or constant power $P=$ const if admittance expressions (1)-(3) are known. The real parts of the coupling coefficients $k_{31}$ and $k_{p}$ for the relations (2) and (3) can be determined in experiments with using the formulae

$$
\begin{gathered}
\frac{k_{310}^{2}}{1-k_{310}^{2}}=\frac{\pi}{2} \frac{f_{n}}{f_{m}} \tan \left[\frac{\left(f_{n}-f_{m}\right) \pi}{2 f_{m}}\right], \\
\frac{2\left(1-k_{p 0}^{2}\right)}{(1+\nu) k_{p 0}^{2}}=\frac{f_{m}^{2}}{f_{n}^{2}-f_{m}^{2}} .
\end{gathered}
$$

Here $f_{m}$ and $f_{n}$ are the frequencies of maximum and minimum admittance respectively, $\nu$ is the Poisson ratio.

The real component of fundamental dimensionless resonance frequency for thin piezoceramic bar with thickness polarization is equal to $\pi / 2$ and for high cylindrical ring with radial polarization it is equal to 1.0. Anti-resonance dimensionless frequencies are determined by coupling coefficients $k_{31}$ or $k_{p}$, which can be written as

$$
\begin{gathered}
k_{31}^{2}=\frac{d_{31}^{2}}{s_{11}^{E} \varepsilon_{33}^{T}}=\frac{d_{310}^{2}}{s_{110}^{E} \varepsilon_{330}^{T}}\left[1+j\left(s_{11 m}+\varepsilon_{33 m}-2 d_{31 m}\right)\right]=k_{310}^{2}\left[1+j\left(s_{11 m}+\varepsilon_{33 m}-2 d_{31 m}\right)\right], \\
k_{p}^{2}=\frac{2}{1-\nu} k_{31}^{2}=\frac{2}{1-\nu} k_{310}^{2}\left[1+j\left(s_{11 m}+\varepsilon_{33 m}-2 d_{31 m}\right)\right]=k_{p 0}^{2}\left[1+j\left(s_{11 m}+\varepsilon_{33 m}-2 d_{31 m}\right)\right] \\
\left(s_{11}^{E}=s_{110}^{E}\left(1-j s_{11 m}\right), \quad \varepsilon_{33}^{T}=\varepsilon_{330}\left(1-j \varepsilon_{33 m}\right), \quad d_{31}=d_{310}\left(1-j d_{31 m}\right), \quad d_{31}^{2}=d_{310}^{2}\left(1-2 j d_{31 m}\right)\right),
\end{gathered}
$$

because electromechanical loss tangents' values are usually small enough.

In our experiments, in parallel to generator's output or coordinating divider, the piezoelement $P e$ and the loading resistors $R$ were included and we could measure for randomly chosen frequency range the voltages $U_{p e}$ on the samples and $U_{R}$ on loading resistors as well as the input voltage $U_{i n}$, the interelectrode capacitance $C_{0}$ and the dielectric loss tangent $\tan \delta=\varepsilon_{33 m}$. The voltage $U_{R}$ is proportional to the electrical current $I_{p e}$ in the resistor and the sample. The loading resistor near the resonance was of $11.2 \mathrm{Ohm}$ and near the anti-resonance $20 \mathrm{kOhm}$.

$$
I_{p e}=\frac{U_{R}}{R}
$$

The ratio of current to voltage is determined as admittance

$$
Y_{p e}=\frac{I_{p e}}{U_{p e}}=\frac{U_{R}}{R U_{p e}}
$$


The product of sample current and sample voltage is determined as instantaneous power

$$
P_{p e}=U_{p e} I_{p e}=\frac{U_{R} U_{p e}}{R} .
$$

The three measured voltages $U_{p e}, U_{R}$, and $U_{i n}$ create peculiar characteristic triangle and the angles between its sides were calculated with using the cosine law [8-10]

$$
\cos \alpha=\frac{U_{p e}^{2}+U_{R}^{2}-U_{i n}^{2}}{2 U_{p e} U_{R}}, \quad \cos \beta=\frac{U_{i n}^{2}+U_{R}^{2}-U_{p e}^{2}}{2 U_{i n} U_{R}}, \quad \cos \gamma=\frac{U_{i n}^{2}+U_{p e}^{2}-U_{R}^{2}}{2 U_{i n} U_{p e}} .
$$

The angle $\alpha$, formed sides $U_{R}$ and $U_{p e}$, characterizes the change of phases between the current and voltage drop in the piezoelement. The angle $\beta$, formed by the sides $U_{i n}$ and $U_{R}$ corresponds to the phase shift between the output voltage of generator and consumable current. The angle $\gamma$, formed by the sides $U_{i n}$ and $U_{p e}$, characterizes the difference of phases between the output voltage of generator and voltage drop on the piezoelement.

The voltages $U_{p e}, U_{R}$, and $U_{i n}$ for "as it is" case together with according frequencies were entered in PC and admittance's, impedance's, angle's and power's amplitude-frequency characteristics (AFChs) were plotted with using the formulae (6), (12)-(15).

To model the constant current, the constant voltage or the constant power loading regimes the following simple transition formulae were derived

$$
\begin{gathered}
U_{i n}=U_{i n 00}, \quad U_{p e}=U_{i n 00} U_{p e 0} / U_{i n 0}, \quad U_{R}=U_{i n 00} U_{R 0} / U_{i n 0} ; \\
U_{R}=U_{R 00}, \quad U_{i n}=U_{R 00} U_{i n 0} / U_{R 0}, \quad U_{p e}=U_{R 00} U_{p e 0} / U_{R 0} ; \\
U_{p e}=U_{p e 00}, \quad U_{i n}=U_{p e 00} U_{i n 0} / U_{p e 0}, \quad U_{R}=U_{p e 00} U_{R 0} / U_{p e 0} ; \\
p_{0}=p_{00}, \quad t=\left[p_{0} /\left(U_{R 0} U_{p e o}\right)\right]^{1 / 2}, \quad U_{p e}=U_{p e 0} t, \quad U_{R}=U_{R 0} t, \quad U_{i n}=U_{i n 0} t .
\end{gathered}
$$

Here $U_{i n 00}, U_{R 00}, U_{p e 00}, p_{00}$ are the constant amplitude values which are taken for modelling while $U_{i n 0}, U_{R 0}, U_{p e 0}$ are ones for "as it is" regime.

\section{Experimental-computational determination of the coupling factors and loss coeffi- cients}

It is necessary to know the coupling factors and loss coefficients to calculate any amplitude for piezoresonator's vibrations. There are a number of experimental methods to determinate their works [6,15-17]. We used the simple experimental-analytical iterative process, which permits to obtain the refined values based on experimental data. This method was described in Ref [8] for the case of radial vibration of thin disk, but imaginary part of the Poisson ratio was neglected.

In the case of thin piezoelectric bar, the iterative process is the following.

For determination of transversal EMCC (electro-mechanic coupling coefficient) $k_{31}$, and tangents of mechanical $s_{11 m}$ and piezoelectric $d_{31 m}$ losses of energy, the iterative steps were made for the basic longitudinal resonance of TsTBS-3 bar with sizes $33.4 \times 5.8 \times 1.25 \mathrm{~mm}$. The sample had $C_{0}=2.98 \mathrm{nF}, \tan \delta=\varepsilon_{33 m}=0.0093, Y_{m}=11.6 \mathrm{mS}, Y_{n}=0.0637 \mathrm{mS}\left(Z_{n}=15.7 \mathrm{k} \Omega\right), f_{m}=51.01 \mathrm{kHz}$, $f_{n}=53.04 \mathrm{kHz}, f_{n} / f_{m}=1.0398, a=0.608 \mathrm{mS}, x_{01}=1.571$. The loading resistor was of 229 Ohms. The multiplier $a$ serves to coordinate dimensionless and resonant frequencies and it is introduced as

$$
\omega C_{0}=2 \pi f_{01} C_{0} x / x_{01}=a x, \quad\left(a=2 \pi f_{01} C_{0} / x_{01}\right),
$$

where $x$ is the current value of dimensionless complex frequency, $x_{01}$ is the active component of dimensionless frequency and $f_{01}$ is the measured frequency of maximum admittance. 
Fig. 1 illustrates three iterative steps. For the sake of greater obviousness, the plots of complete conductivity are given to the first row and the sample impedance is represented at the second row. Graphs for every step are similar and they differ only with amplitudes and frequency positions of a minimum of conductivity (or a maximum of impedance).

As a result of first iteration which was made in the interval of dimensionless frequencies $1.5 \leqslant x \leqslant 1.75$ at the following chosen values $k_{310}^{2}=0.1, s_{11 \mathrm{~m}}=0.01, \varepsilon_{33 \mathrm{~m}}=0.0093, d_{31 \mathrm{~m}}=0.01$; $a=0.608 \mathrm{mS}$ the following conductivities $Y_{m}=7.8 \mathrm{mS}, Y_{n}=0.112 \mathrm{mS}$ and frequencies $x_{n}=1.64$, $x_{m}=1.571, x_{n} / x_{m}=1.0446$ were obtained (Fig. 1,a). It is required to diminish the ratio $x_{n} / x_{m}$, and it can be done only with diminishing of $k_{310}^{2}$, and for $Y_{m}$ increasing it is necessary to diminish $s_{11 m}$.

The next iteration was provided in the same frequency range at other set of values: $k_{310}^{2}=0.09$, $s_{11 m}=0.006, \varepsilon_{33 m}=0.0093, d_{31 m}=0.007, a=0.608 \mathrm{mS}$. The conductivities $Y_{m}=11.7 \mathrm{mS}$, $Y_{n}=0.0735 \mathrm{mS}$ and frequencies $x_{n}=1.6321, x_{m}=1.571, x_{n} / x_{m}=1.0389$ were got (Fig. $1, b$ ). Maximum of the complete conductivity and ratio of frequencies approach experimental values, but for diminishing of conductivity minimum it is necessary to reduce the tangent of piezoelectric losses. Last (fifth) iteration was conducted in the same frequency interval at $d_{31 m}=0.004$. We obtained the conductivities $Y_{m}=11.7 \mathrm{mS}, Y_{n}=0.0684 \mathrm{mS}$ and frequencies $x_{n}=1.6321, x_{m}=1.571, x_{n} / x_{m}=1.0389$ (Fig. 1, c). The differences between the experimental and calculated data for $Y_{m}, Y_{n}$ and $f_{n} / f_{m}$ are $0.86 \%, 7.4 \%$, and $0.03 \%$ respectively.
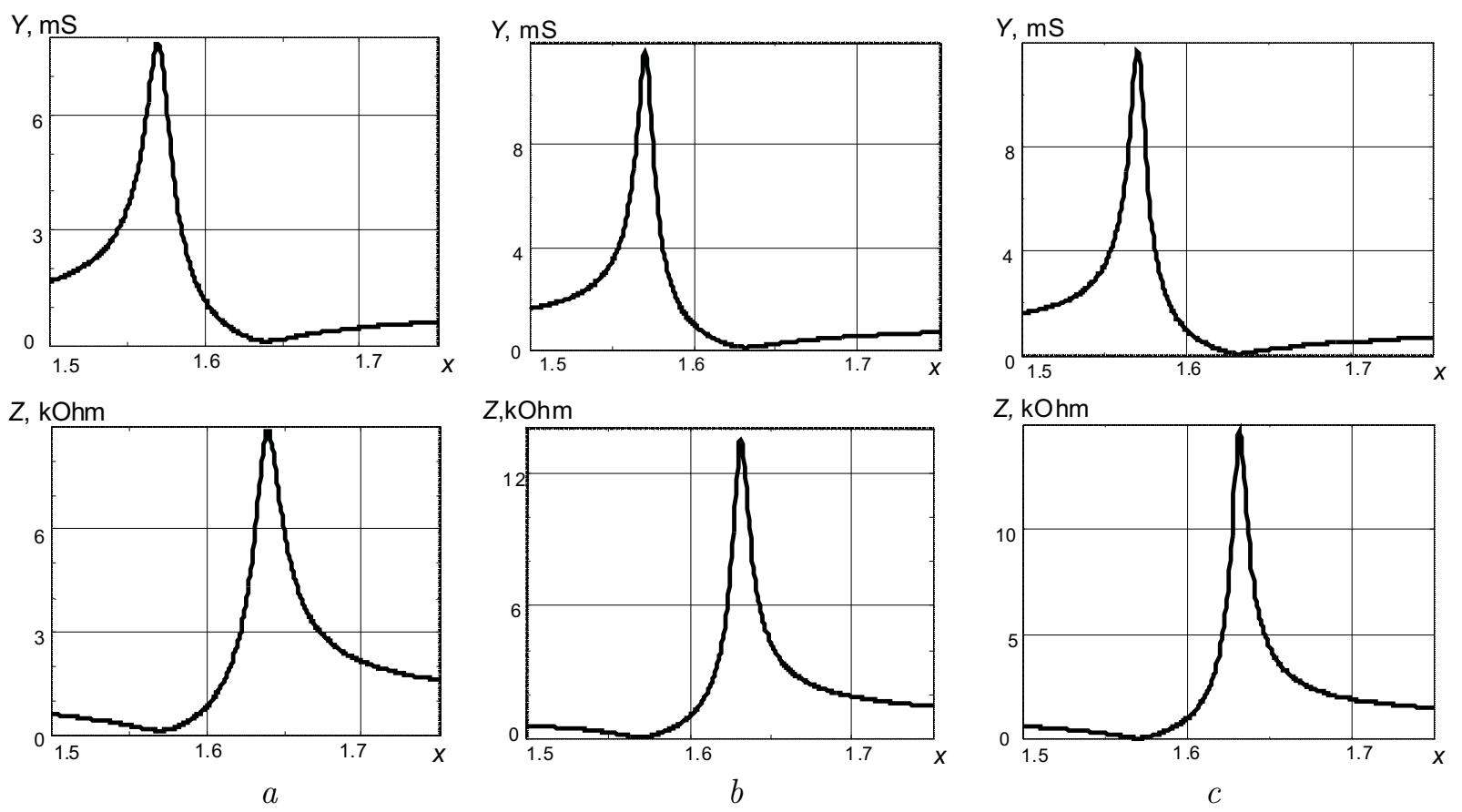

Fig. 1. Stages of iterative process for a bar with $33.4 \times 5.8 \times 1.25 \mathrm{~mm}$ dimensions made of TsTBC-3 ceramics.

As the result of iterative procedures, it is possible to consider the following: $k_{310}^{2}=0.09$; $s_{11 m}=0.006 ; \varepsilon_{33 m}=0.0093 ; d_{31 m}=0.004$. This information may be used for calculations of admittances, impedances, powers, displacements, strains or stresses in any point of a thin piezoelectric bar.

Analogical iterative procedure was made for shot and high piezoelectric cylindrical rings with radial polarization.

We made such steps in the case of radial vibrations of a high ring.

In Fig. 2 the admittance modulus is plotted as dashed line, the real part of the admittance is plotted as solid line and the imaginary part of the admittance is plotted as dotted line. The right graphs refine the interval near the minimum admittance. 

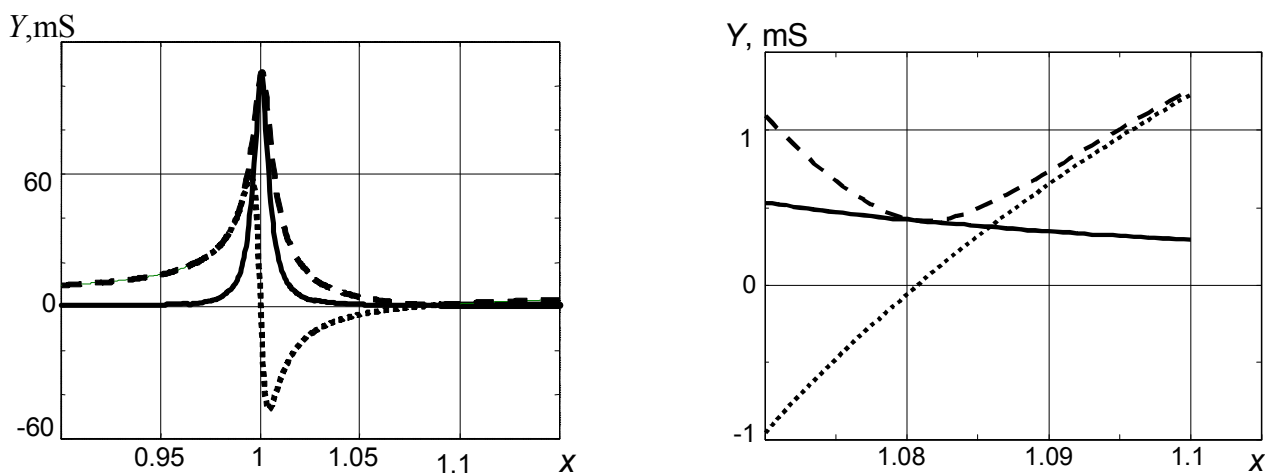

$a$
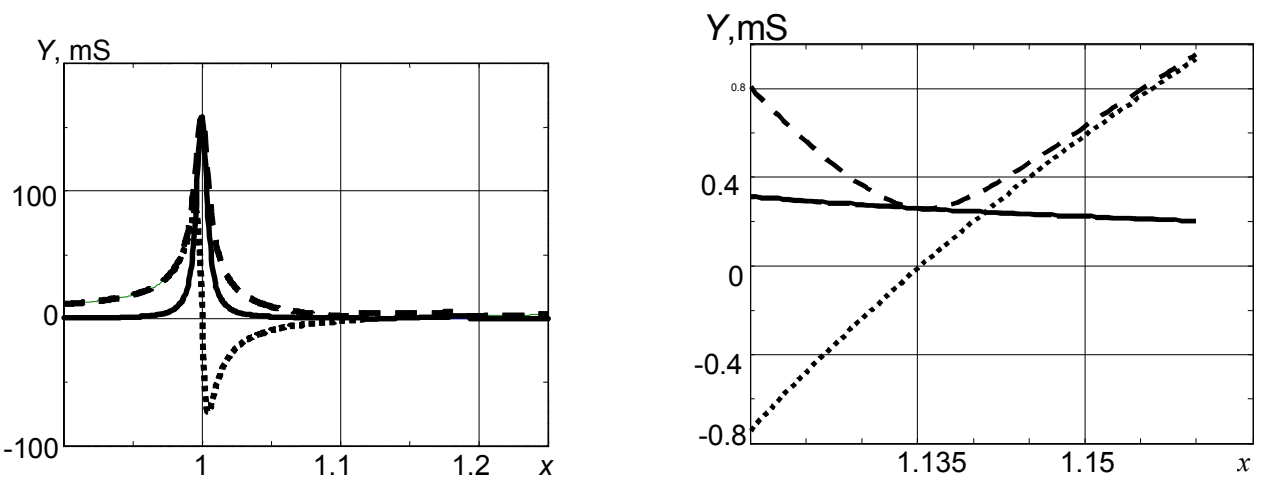

$b$
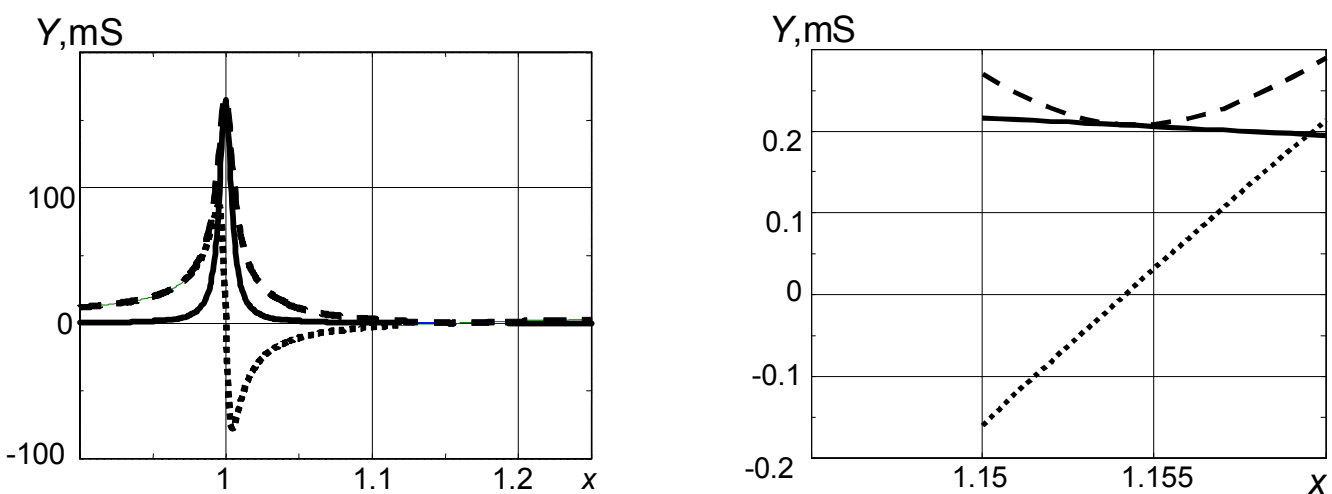

$c$

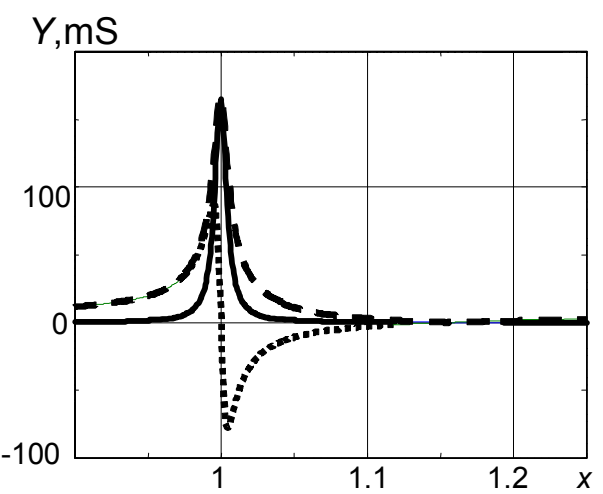

\section{Y.mS}

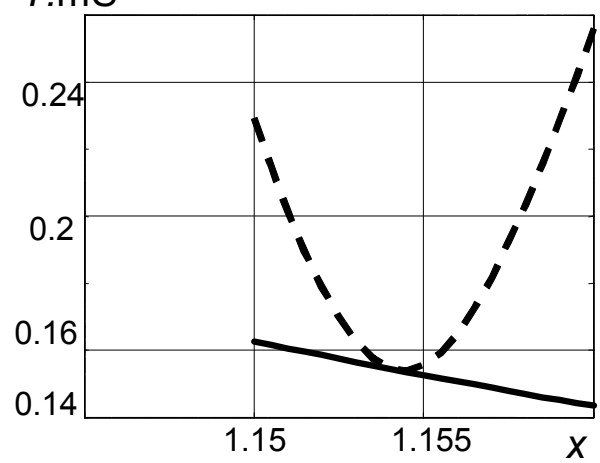

$d$

Fig. 2. An iterative process for cylindrical shell with $18.5 \times 15.7 \times 22 \mathrm{~mm}$ sizes made from TsTS-19 ceramics. 
The first iteration step (Fig. 2,a) was performed with the following data (cylindrical shell with dimensions $18.5 \times 15.7 \times 22 \mathrm{~mm}$ made of TsTS-19 ceramics): $C_{0}=14480 \mathrm{pF}, \varepsilon_{33 \mathrm{~m}}=0.0104, a=7.02 \mathrm{mS}$, $\nu=0.35, k_{p}^{2}=0.2, s_{11 m}=0.009, d_{31 m}=0.012$. The measured data were: $Y_{m}=170 \mathrm{mS}, Y_{n}=0.14 \mathrm{mS}$, $f_{m}=77.789 \mathrm{kHz}, f_{n}=90.039 \mathrm{kHz}, f_{n} / f_{m}=1.1574$. The resistance of loading resistor at the resonance was equal to $11.2 \mathrm{Ohm}$ and at anti-resonance was equal to $229 \mathrm{Ohm}$.

The calculated results $x_{m}=1.0, Y_{m}=106 \mathrm{mS}, x_{n}=1.081, Y_{n}=0.4 \mathrm{mS}, x_{n} / x_{m}=1.081$ are not in agreement with the experimental data. It is necessary to increase $k_{p}^{2}$ value.

For the case of $k_{p}^{2}=0.3$ (second step, Fig. $2, b$ ) the results $x_{m}=1.0, Y_{m}=106 \mathrm{mS}, x_{n}=1.1357$, $Y_{n}=0.26 \mathrm{mS} ; x_{n} / x_{m}=1.1357$ are in pure agreement with the experiment data. For the case of $k_{p}^{2}=0.33$ (third step Fig. $\left.2, c\right)$ the results $x_{m}=1.0, Y_{m}=170 \mathrm{mS}, x_{n}=1.154, Y_{n}=0.21 \mathrm{mS}$, $x_{n} / x_{m}=1.154$ are in agreement with the experimental data. Decreasing of piezoelectric loss tangent to a level $d_{31 \mathrm{~m}}=0.0067$ (fourth step, Fig. $2, d$ ) decreases the admittance minimum to value $Y_{n}=0.153 \mathrm{mS}$.

The iterative results $x_{m}=1.0, Y_{m}=170 \mathrm{mS}, k_{p}^{2}=0.33, s_{11 m}=0.0095, \varepsilon_{33 m}=0.0104$, $d_{31 m}=0.0067, x_{n}=1.154, Y_{n}=0.153 \mathrm{mS} ; x_{n} / x_{m}=1.154$ are in very good agreement with experimental data: $Y_{m}=170 \mathrm{mS}, Y_{n}=0.14 \mathrm{mS}, f_{m}=77.789 \mathrm{kHz}, f_{n}=90.039 \mathrm{kHz}, f_{n} / f_{m}=1.1574$. The discrepancy for $Y_{m}$ is $0 \%$, for $Y_{n}$ is $9.3 \%$ and for $f_{n} / f_{m}$ is $0.26 \%$.

Thus, for mentioned higher cylindrical shell the following refined data $k_{p}^{2}=0.33, d_{31 m}=0.0067$, $s_{11 m}=0.0095, \varepsilon_{33 m}=0.0104$ were obtained.

\section{The simulation of the electrical loading of piezoelectric elements on the basis of experimental data}

To estimate influence of the chosen electric loading regime on piezoceramic bar with dimensions $33.4 \times 5.8 \times 1.25 \mathrm{~mm}$ made of TsTBC-3 ceramics, the forced vibrations amplitude-frequencies characteristics (AFChs) were plotted for the following cases: "as it is", constant sample current, constant sample voltage and constant sample power (Fig. 3). The conversion from one type of loading conditions to other is performed using the formulae (16). The plots in the first row are given for "as it is" case, the second row responds the constant current permanent amplitude of $1 \mathrm{~mA}$, the third row brings results for the case when the sample voltage level equals $100 \mathrm{mV}$ (such value was experimentally got at resonance) and the fourth row represents a case of the constant instantaneous power level $0.218 \mathrm{mVA}$. The voltage drops $U_{i n}$ (solid lines), $U_{p e}$ (dashed curves) and $U_{R}$ (dotted lines) are given in the first column.

The second and third columns are accordingly built for AFChs of full conductivity and instantaneous power. AFChs of the phase angles $\alpha$ (solid lines), $\beta$ (dotted lines) and $\gamma$ (dashed curves) are resulted in the fourth column.

The analysis of the graphs shows the following facts. The regime of the electric loading does not influence AFChs of full conductivity and phase shifts - they remain without changes at the change of external electric conditions. At the same time, AFChs of instantaneous power and voltages strongly depend on the chosen loading regime. At approaching to resonance in the regime "as it is" the voltage $U_{i n}$ goes down (due to shunting operating of measuring circuit on the output of generator or coordinating voltage divider). Sharp growth of the loading resistor voltage $U_{R}$ and decline of voltage drops $U_{p e}$ on piezoelement take place. And at nearing to anti-resonance the voltage drops on the loading resistor goes down and arrives at a minimum on certain frequency which is equated with anti-resonance [5-7].

Forced vibrations of piezoelectric high cylindrical ring of $18.5 \times 15.7 \times 22 \mathrm{~mm}$ sizes made of TsTS19 ceramics were studied in "as it is" regime with two loading resistor of 11.2 and $229 \mathrm{Ohm}$. It was established that the admittance maximum changes from 167 to $160 \mathrm{mS}$ (difference is $4.3 \%$ ) only, while impedance maximum changes from 1.22 to $7.3 \mathrm{kOhm}$ (almost 6 times!).

Fig. 4 demonstrates the admittance's AFChs at loading resistor 11.2 (first and second graphs) and 229 Ohm resistance (third and fourth graphs). These graphs are plotted for regimes: "as it is" (first 

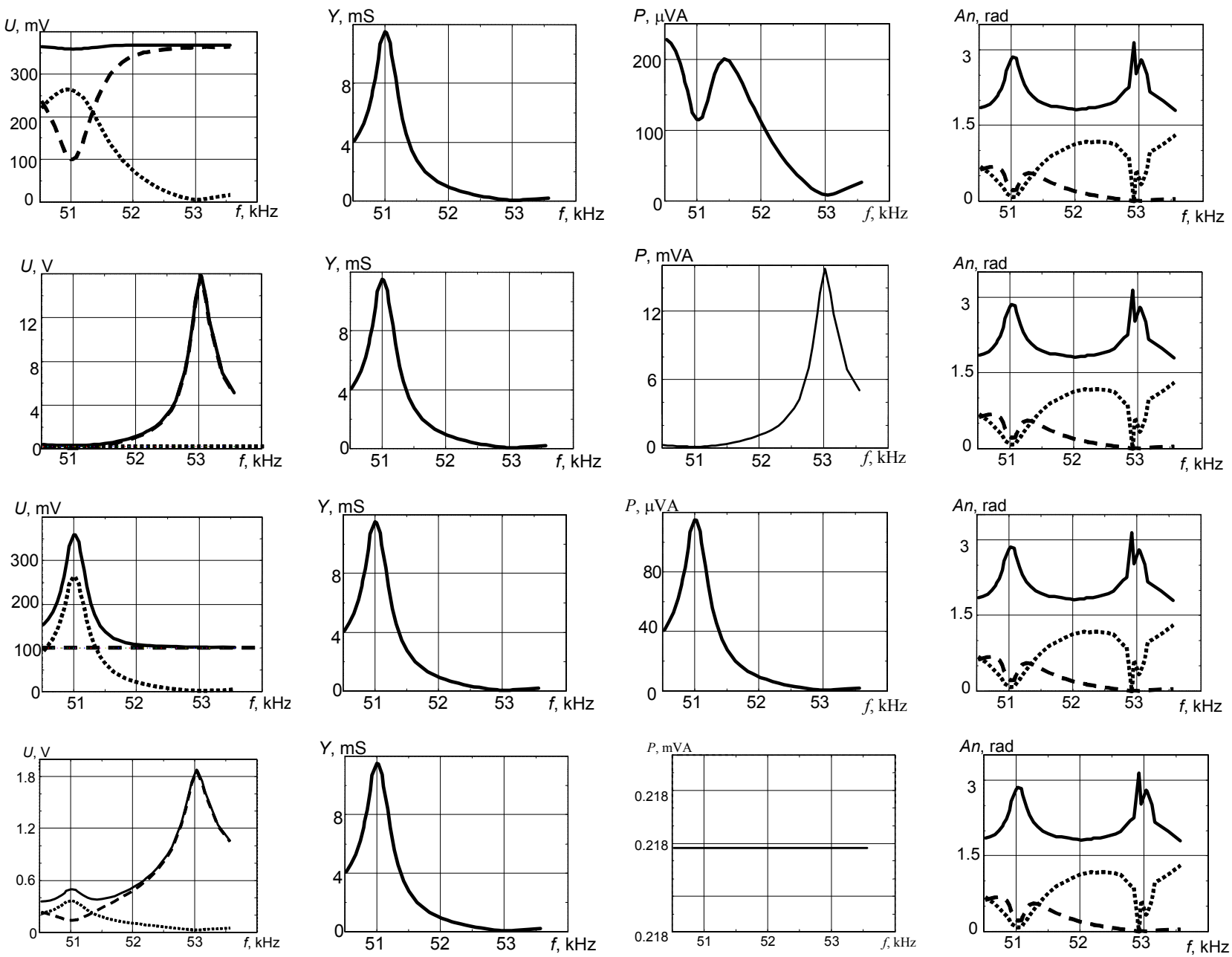

Fig. 3. Amplitude-frequency characteristics of voltage, admittance, power and phase angles for a bar with $33.4 \times 5.8 \times 1.25 \mathrm{~mm}$ dimensions made of TsTBC-3 ceramics.
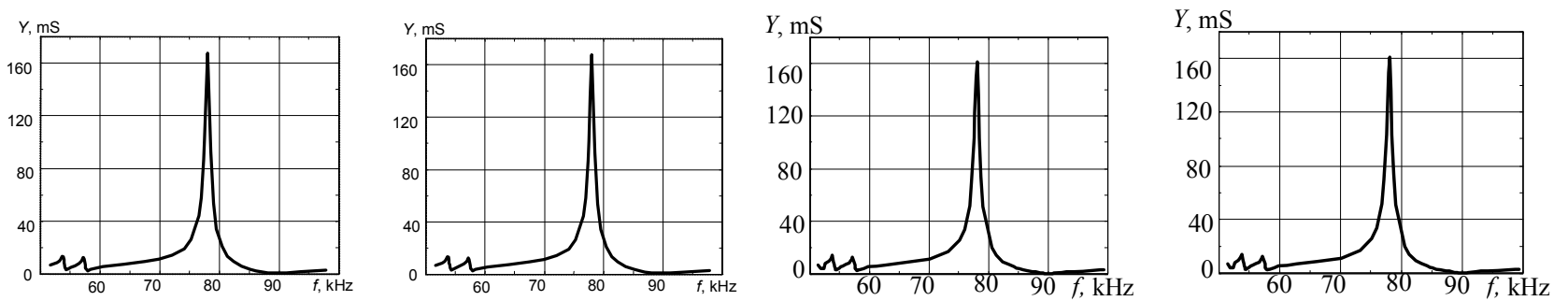

Fig. 4. Amplitude-frequency characteristics of admittance for a high cylindrical ring at loading resistor 11.2 and $229 \mathrm{Ohm}$.

and third curves) or constant power (second and fourth curves). Admittance's AFChs do not depend on electric loading regimes and they are weakly depending on loading resistor value.

Fig. 5 illustrates the voltage's AFCh (first column), impedance's AFCh (second column), instantaneous power's AFCh (third column) and phase angles' AFCh (fourth column) of high ring for regimes "as it is" (first row) and after transformation data into the regimes of constant sample current (second row), constant sample voltage (third row) or constant sample power (forth row) with using the formulae (16) at the loading resistor of $11.2 \mathrm{Ohm}$ resistance. Graphs are plotted for frequency range $50-100 \mathrm{kHz}$, in which two weak resonances and one strong resonance are observed.

Fig. 6 demonstrates the same AFChs at loading resistor 229 Ohm resistance.

Fig. 3-6 show that the influence of electric loading conditions on the vibrations' parameters of piezoelectric ceramic sample is different for voltage drops, instant powers and admittance/impedance. 

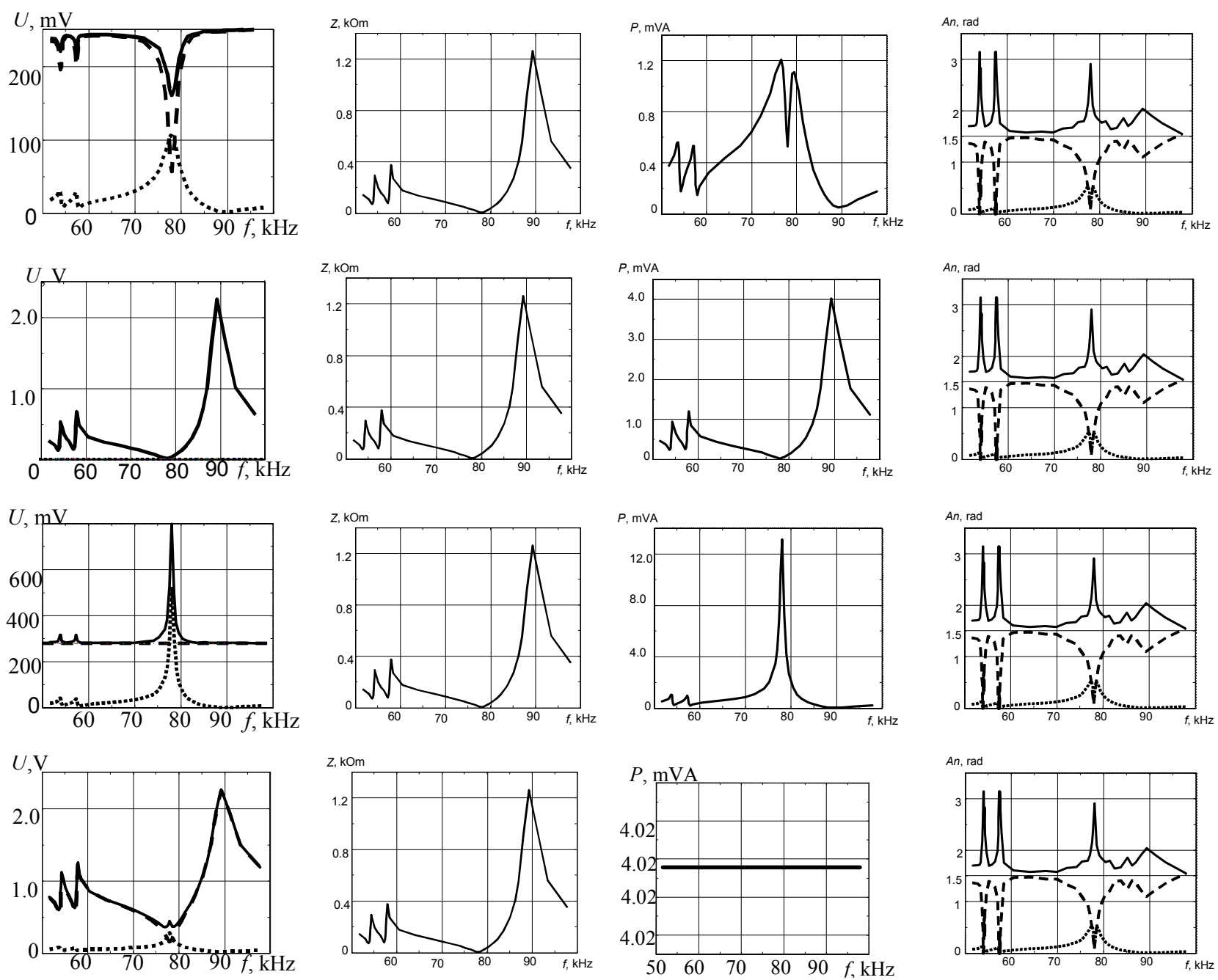

Fig. 5. Amplitude-frequency characteristics of voltage, impedance, power and phase angles for a high ring with $18.5 \times 15.7 \times 22 \mathrm{~mm}$ dimensions made of TsTS-19 ceramics and loading resistor $11.2 \mathrm{Ohm}$.

Although piezoceramic materials are known as nonlinear substance, our experience and literature data testify that they may be regarded as almost linear for electric field up to $1000 \mathrm{~V} / \mathrm{m}$ level range. All the graphs in this paper were built for linear approximations. The experimental investigation for thin piezoceramic disk radial vibrations at the constant input voltage, constant sample voltage, and constant sample current corroborated such intention [8].

\section{Discussion of modeling results}

Graphs of input $U_{i n}$ and sample $U_{p e}$ voltages partly or fully coincide after transformations from "as it is" regime to the constant current and the constant power regimes. These curves are not separated on black-white Figs.

In the regimes of constant sample current and constant sample voltage, the frequency locations of instant power's maxima coincide with frequency locations of input voltage maxima. In regimes "as it is" the "failures" at resonance are observed in AFChs of instant power that may be a result of part of power reduction by loading resistor. It is necessary to increase of the input voltage at anti-resonance to realize the constant sample current regime and at resonance for realization of the constant sample voltage regime.

Regimes of constant instantaneous power may be realized with simultaneous increasing both the resonant and anti-resonant input voltage. The degree of such increasing depends on loading resistor 

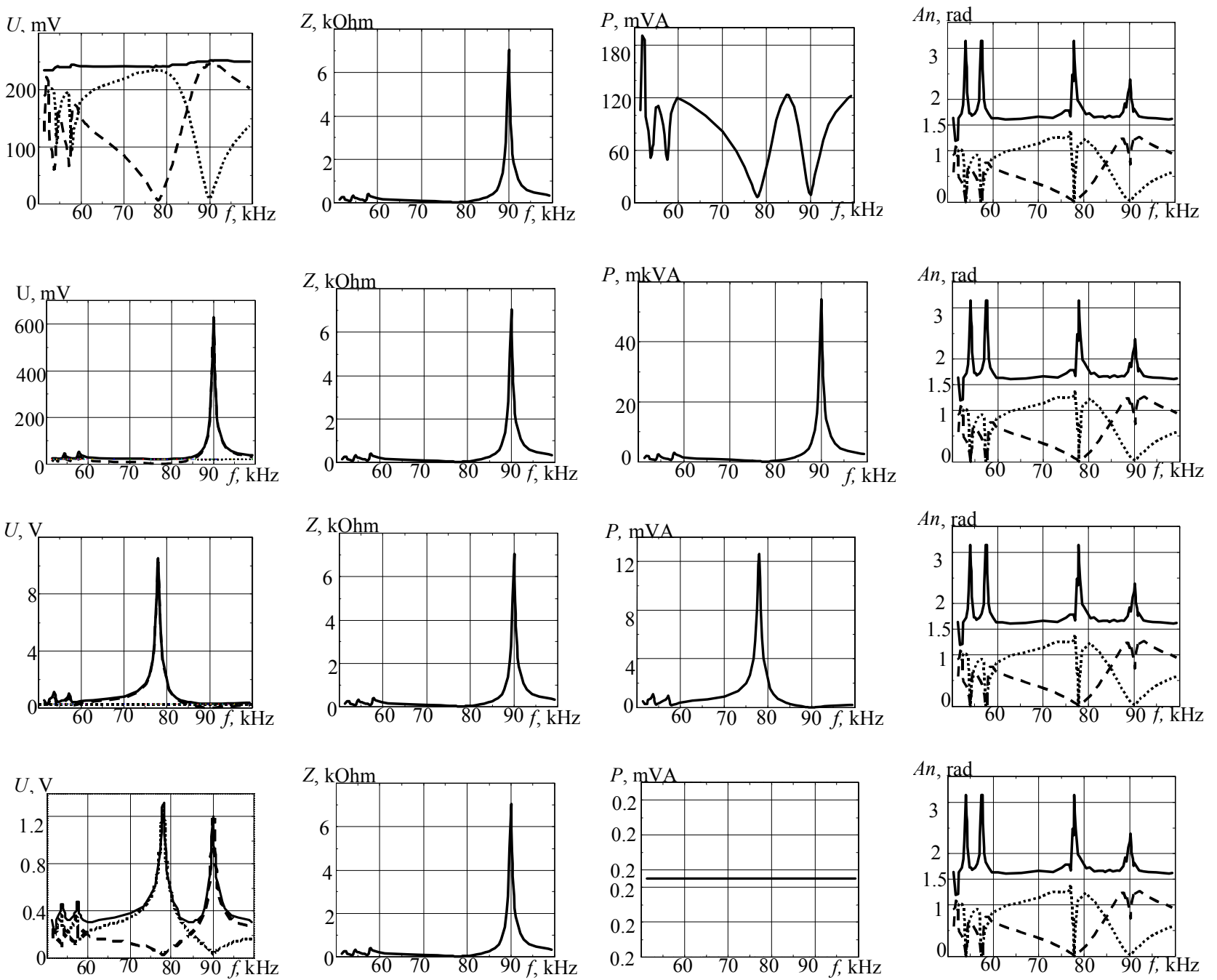

Fig. 6. Amplitude-frequency characteristics of voltage, impedance, power and phase angles for high ring with $18.5 \times 15.7 \times 22 \mathrm{~mm}$ dimensions made from TsTS-19 ceramics at loading resistor $229 \mathrm{Ohm}$.

value and consists of a number of tens percents near resonance to several times near anti-resonance as compared to off-resonance case. Loading resistor value influences anti-resonance admittance and impedance in many times and in several tens of percents at resonance. Impedance's AFChs for 229 Ohm loading resistance are sharper then for $11.2 \mathrm{Ohm}$ case.

The phase shift between sample voltage and sample current (angle $\alpha$ ) reaches $\pi$ radian at resonances and anti-resonances and it changes from $\pi / 2$ to $\pi$ in frequency range. The phase shift between output voltage of generator or voltage divider and consumable current (angle $\beta$ ) is equal to $\pi / 2$ radian in frequency range. It declines to zero at resonances and anti-resonances. And difference of phases between output voltage of generator (voltage divider) and voltage drop on piezoelement (angle $\gamma$ ) declines to zero at resonances and may reach $\pi / 2$ radian level at off-resonance frequencies.

\section{Conclusions}

Amplitude-frequency characteristics for piezoelectric bars, disks, short and high cylindrical rings which were obtained at the S. P. Timoshenko Institute of Mechanics of NASU (Department of electroelasticity) shown that electric loading regimes do not influence admittance, impedance and phase angles.

The independence of these parameters from electrical loading regimes are explained simply - relations between voltage drops $U_{i n}, U_{p e}$, and $U_{R}$ are not changed. But voltage drop level and instantaneous power are very sensitive to the electric loading conditions. 
Two modeling techniques were described in this paper: an iterative process and electric loading condition simulation. Iterative results for both thin piezoelectric ceramic bar and high cylindrical ring show that the energy-loss elastic, dielectric and piezoelectric tangents have commensurate values.

For modeling the constant power regime, it is necessary to increase the input voltage and the sample voltage near resonance by $30-40 \%$ and in several times at anti-resonance as compared to off resonance case.

The Refs $[1-3,16]$ results may be explained in the following way.

When piezoelectric sample is excited by constant voltage the instantaneous power in sample increases at resonance frequency in many times as compared to off-resonance case. And when a sample is excited by constant current, the instantaneous power in the sample decreases at resonance frequency in that ratio. Thus, the cause of admittance curve nonlinearity at constant voltage and its absence at constant current is upper or lower level of an instantaneous power.

The linear approximation for transformation of measured data permits us to study main features of the piezoelectric resonators' vibrations without mathematical and experimental difficulties. Such methodology gives us the possibility to make clear the general tendencies in the piezoelectric sample behaviour for various electric loading conditions.

\section{Acknowledgements}

The authors thank S. P. Timoshenko Institute of Mechanics (the National Academy of Sciences of Ukraine) for supports these investigations. They would wish like to acknowledge Dr A. V. Mezheritsky (USA) for collaboration and useful discussions.

[1] Uchino K., Hirose S. Loss mechanisms in piezoelectrics: how to measure different losses separately. IEEE Trans. Ultrason. Ferroelectr. Freq. Control. 48, n.1, 307-321 (2001).

[2] Ural O., Tuncdemir S., Zhuang Yu., Uchino K. Development of a high power piezoelectric characterization system and its application for resonance/antiresonance mode characterization. Jpn. J. Appl. Phys. 48, n.5R, 056509 (2009).

[3] Uchino K., Zheng J. H., Chen Y.H. et al. Loss mechanisms and high power piezoelectric. J. Mat. Sci. 41, 217-228 (2006).

[4] Jaffe B, Cook W. R., Jaffe H. Piezoelectric ceramics. Academic Press, London (1971).

[5] Shul'ga N. A., Bolkisev A. M. The vibrations of piezoelectric bodies. Nauk. Dumka, Kiev (1990) (in Russian).

[6] Shul'ga M. O., Karlash V. L. Resonant electromechanical vibrations of piezoelectric plates. Nauk. Dumka, Kiev (2008) (in Ukrainian).

[7] Karlash V. L. Resonant electromechanical vibrations of piezoelectric plates. Int. Appl. Mech. 41, n.7, 709-747 (2005).

[8] Karlash V. L. Energy losses in piezoceramic resonators and its influence on vibrations' characteristics. Electronics and communication. 19, n.2(79), 82-94 (2014).

[9] Karlash V. L. Methods of determination of coupling factors and energy losses at piezoceramics resonator's vibrations. Acoustic bulletin. 15, n.4, 24-38 (2012) (in Ukrainian).

[10] Karlash V. L. Modeling of energy-loss piezoceramic resonators by electric equivalent networks with passive elements. Mathematical modeling and computing. 1, n.2, 163-177 (2014).

[11] Martin G. E. Dielectric, elastic and piezoelectric losses in piezoelectric materials. Ultrasonic Symp. Proc. Milwaukee. 613-617 (1974).

[12] Mezheritsky A. V. Elastic, dielectric and piezoelectric losses in piezoceramics; how it works all together IEEE Trans UFFC. 51, n.6, 695-797 (2004).

[13] Bezverkhyi O., ZinchukL., Karlash V. An influence of electric loading, constant voltage or current on piezoceramic resonators' vibrations characteristics. Physico-mathematical modeling and information technologies. N.18, 9-20 (2013) (in Ukrainian).

Mathematical Modeling and Computing, Vol.2, No. 2, pp. 115-127 (2015) 
[14] Shul'ga M. O., Karlash V.L. Measurement of piezoceramic elements admittance in Mason's four-pole and its variants. Proc. IV Int. Sci-Tech. Conf. "Sensors, devices and systems - 2008". Cherkasy-Gurzuf. 54-56 (2008) (in Ukrainian).

[15] Glozman I. A. Piezoceramics. Energhiya, Moscow (1972) (in Russian).

[16] Uchino K., Zhuang Yu., Ural S. O. Loss determination methodology for a piezoelectric ceramic: new phenomenological theory and experimental proposals. J. Adv. Dielectric. 1, n.1, 17-31 (2011).

[17] Liu G., Zhang S., Jiang W., Cao W. Losses in ferroelectric materials. Material Science and Engineering. R 89, 1-48 (2015).

\title{
Моделювання умов електричного навантаження п'єзокерамічних резонаторів основане на експериментальних даних
}

\author{
Безверхий О. І., Зінчук Л. П., Карлаш В. Л. \\ Інститут механіки ім. С. П. Тимошенка НАН Украӥни \\ вул. Несторова, 3, 0305\%, Киӥв, Украӥна
}

\begin{abstract}
Проаналізовано проблему моделювання умов електричного навантаження за вимушених коливань п'єзокерамічних резонаторів. Основана на експериментальних даних для режиму "як є" нова проста експериментальна техніка разом з обчисленнями дала змогу вивчати багато параметрів резонатора: адмітанс, імпеданс, фазові кути, компоненти потужності тощо для електричних умов сталої вхідної напруги, сталої напруги на зразку, сталого струму в зразку. Таке комп'ютерне моделювання робить можливим зменшувати експериментальні труднощі й вивчати в лінійному наближенні залежність параметрів резонатора від умов навантаження. Основні моди коливань тонкого п'єзоелектричного стержня і високої циліндричної оболонки подані як приклад. Встановлено, що значна нелінійність адмітансу в режимі сталої напруги та їі відсутність для випадку сталого струму спричинені різною поведінкою рівня миттєвої потужності.
\end{abstract}

Ключові слова: вимушені коливання, п'езокерамічних резонаторів, електромеханічний зв'язок, тонкі п'єзоелектричні пластини й оболонки, миттева потужність

2000 MSC: 74-05, 74F $15,74 \mathrm{H} 45$

УдК: 534.1:537.226.86:539.3

Mathematical Modeling and Computing, Vol.2, No. 2, pp. 115-127 (2015) 